\title{
Avaliação do estresse ocupacional no cotidiano de policiais militares do Rio Grande do Sul
}

\section{Assessment of occupational stress in everyday of Police Military of Rio Grande do Sul}

\author{
DAMIANA MACHADO DE ALMEIDA* \\ LUIS FELIPE DIAS LOPES** \\ VANIA MEDIANEIRA FLORES COSTA*** \\ RITA DE CÁSSIA TRINDADE DOS SANTOS*** \\ JONATHAN SAIDELLES CORR $\hat{E} A^{* * * * *}$
}

\section{RESUMO}

Estresse se configura em uma ameaça real, percebida ou socialmente construída. Segundo Marras e Veloso (2012), é um processo ou o seu resultado, compreendendo desde as reações biológicas e psicológicas até as ações decorrentes para examinar o estressor. Desse modo, este estudo foi desenvolvido visando a identificar o nível de estresse ocupacional dos policiais militares do Rio Grande do Sul. Realizou-se uma pesquisa descritiva, do tipo survey, com abordagem quantitativa. Os participantes do

* Doutoranda em Administração no Programa de Pós-Graduação em Administração da Universidade Federal de Santa Maria. E-mail: adm.damiana@gmail.com

* Doutor em Engenharia de Produção. Professor Associado do departamento de ciências administrativas na Universidade Federal de Santa Maria. E-mail: 1flopes67@yahoo.com.br

*** Doutora em Administração. Professora adjunta do departamento de ciências administrativas na Universidade Federal de Santa Maria. E-mail: vania.costa@ufsm.br

**** Mestranda em Administração no Programa de Pós-Graduação em Administração da Universidade Federal de Santa Maria. E-mail: rita.santos0606@gmail.com

***** Mestrando em Administração no Programa de Pós-Graduação em Administração da Universidade Federal de Santa Maria. E-mail: jonathan.saidelles@gmail.com 
estudo totalizaram 519 policiais militares pertencentes a quartéis de cidades localizadas no estado do Rio Grande do Sul. No geral, ocorreu predomínio do nível médio de estresse, com os seguintes estressores com as maiores médias: deficiência nos treinamentos para capacitação profissional $(3,51)$; discriminação/favoritismo no ambiente de trabalho $(3,40)$; poucas perspectivas de crescimento na carreira $(3,37)$; pouca valorização por parte dos superiores $(3,04)$; e, por fim, deficiência na divulgação de informações sobre as decisões organizacionais $(3,00)$.

Palavras-chave: Estresse ocupacional; policiais militares; trabalho.

\section{Abstract}

Stress is configured in a real threat, perceived or socially constructed. According Marras and Veloso (2012), is a process or its outcome, ranging from biological and psychological reactions to the actions arising to examine the stressor. Thus, this study was developed to identify the level of occupational stress of the Military Police of Rio Grande do Sul. We conducted a descriptive research, survey type, with a quantitative approach. Study participants totaled 519 military police belonging to cities located barracks in the state of Rio Grande do Sul Overall, there was a predominance of the average level of stress, with the following stressors with the highest average: deficiency in training for vocational training $(3,51)$; discrimination/favoritism in the workplace (3.40); few growth prospects in career (3.37); little appreciation by superiors (3.04); and, finally, deficiency in the dissemination of information on organizational decisions (3.00).

Keywords: Occupational stress; Military Police; work.

\section{INTRODUÇÃo}

Em virtude do contexto cada vez mais dinâmico e competitivo da sociedade moderna, o trabalho vem ocupando uma parcela cada vez maior da vida da maioria das pessoas. Inúmeros são os aspectos presentes na rotina de trabalho que influenciam diretamente o desempenho individual de cada trabalhador. Quando essas influências são negativas, podem acarretar prejuízos aos colaboradores, ocasionando o estresse ocupacional. As tecnologias, o ritmo de trabalho, a pressão por resultados, as relações entre a equipe, a afetividade ou 
a falta dela e a estrutura de trabalho são alguns dos aspectos que atingem diretamente as pessoas.

Desse modo, o desenvolvimento de alguns estudos que contribuam para o aprofundamento de questões relativas ao estresse no ambiente de trabalho demonstra ser necessário em virtude do contexto em que estão inseridas as organizações (BRASIL, 2001). Do mesmo modo, Paschoal e Tamayo (2004) mencionam que a maior ocorrência de pesquisa sobre estresse se deve em razão do seu impacto negativo sobre a saúde e o bem-estar do trabalhador, influenciando a produtividade e o funcionamento da organização. Essas consequências motivam a busca por estratégias que possam dirimir ou eliminar seus efeitos prejudiciais.

Nesse intuito, o estresse é compreendido como um processo ou como resultado deste. Em se tratando de processo, o estresse compreende as reações biológicas e psicológicas do indivíduo e as ações decorrentes para lidar com o estressor; este é uma ameaça real, percebida ou socialmente construída (MARRAS; VELOSO, 2012).

Com base no exposto, inserem-se os estudos com os policiais militares, os quais estão a mercê de inúmeras situações que conduzem ao estresse, principalmente em função dos riscos provenientes das atividades de rotina (COSTA et al., 2007). Entre as principais funções estão: assegurar o cumprimento da lei e a manutenção da ordem pública; ir de encontro à perturbação da ordem pública e agir no gerenciamento de situações de alto risco; realizar os serviços de busca e salvamento aéreo, aquático e terrestre; e executar a guarda de estabelecimentos prisionais do estado.

Essas atividades exercidas pelo policial militar são de alto risco, pois estão diariamente relacionadas à violência e à brutalidade. Isso está de acordo com Costa et al. (2007) e Oliveira e Bardagi (2010), quando afirmam que as situações adversas encaradas por policiais militares tornam essa profissão uma das mais propensas ao estresse. Desse modo, o presente estudo tem por objetivo identificar o nível de estresse ocupacional dos policiais militares do estado do Rio Grande do Sul.

A relevância desta pesquisa está relacionada aos benefícios que seus resultados possibilitaram aos gestores, policiais militares e sociedade, haja vista que o panorama relativo ao estresse ocupa- 
cional contribui para a implementação de ações necessárias para auxiliar esses profissionais a sobreviverem ao rigor da profissão. Por sua vez, destaca-se a relevância científica do presente estudo na medida em que se propõe a contribuir para melhor compreensão sobre o estresse ocupacional no contexto de policiais militares, podendo vir a preencher possíveis lacunas que porventura ainda existam sobre o tema.

Além da introdução, que contextualiza a pesquisa e apresenta o seu objetivo; e das considerações finais, em que se enfatiza a relevância dos achados do estudo; o presente artigo é apresentado em três partes. A primeira delas traz uma breve revisão de literatura acerca das temáticas estresse e estresse ocupacional. Já a segunda parte descreve o método utilizado para atingir o objetivo, e a terceira se volta para discutir os resultados encontrados, bem como as limitações da pesquisa em questão.

\section{ESTRESSE E ESTRESSE OCUPACIONAL: ASPECTOS E CONCEITOS}

O período pós-revolução industrial provocou inúmeras mudanças que influenciaram o ambiente de trabalho nas organizações. Entre elas, destacam-se o aumento da influência da tecnologia, a elevação da competitividade e a preocupação com a maximização da eficiência. Para Camelo e Angerami (2008), a evolução tecnológica trouxe contribuições para o desenvolvimento do homem em seu contexto social, cultural e biológico; contudo, também expôs sua fragilidade física e emocional. Em virtude desse cenário, surgem inúmeros relatos de fatores que propiciam ao homem exaustão física e psicológica que, por sua vez, conduzem ao estresse.

A definição de estresse é proveniente do século XVII, porém somente em 1926 um dos principais estudiosos do tema, Hans Selye, passou a descrever o estresse como um estado de tensão do organismo (LIPP, 2000). Porém, a banalização do tema faz com que a sociedade o empregue de maneira generalizada. Pereira (2002) menciona que essa popularização da definição de estresse fez com que fosse considerado sinônimo de qualquer comportamento negativo incomum.

Embora o conceito seja amplamente utilizado de maneira informal, no âmbito científico ele é controverso entre os pesquisadores. 
Isso porque diversas áreas da ciência o utilizam como objeto de estudo, principalmente as relacionadas às ciências biológicas, sociais e humanas. Em decorrência disso, Faro e Pereira (2013) afirmam que geralmente há ênfases distintas sobre o fenômeno na literatura, referindo-se geralmente aos agentes estressores, à mediação cognitiva ou às consequências sobre a saúde.

O estresse é um estado em que o corpo emite reações a várias situações ambientais, físicas e sociais (FERRAZ; FRANCISCO; OLIVEIRA, 2014). Ou seja, quando afetada a homeostase do indivíduo, o organismo emite respostas buscando restabelecer o equilíbrio interno. Tamayo (2007, p. 25) salienta que os fatores influenciadores podem ser tanto externos quanto internos:

O estresse pode ser considerado como mecanismo utilizado pelas pessoas para se adaptarem às exigências do meio externo ou para responderem a metas que fixam para si próprias. Características do meio externo podem estimular o indivíduo a se engajar em atividades cada vez mais complexas, desenvolvendo assim o seu potencial.

No entanto, nem todo estresse é prejudicial. Bianchi (2001) defende que o estresse também pode adotar conotação positiva, em que o indivíduo assume o evento estressante como um desafio. De acordo com Bonez, Dal Moro e Sehnem (2013, p. 514), "é natural e até esperado que o ser humano experimente algum desconforto ocasional, que se assemelha aos sintomas de estresse". Abreu et al. (2002, p. 25) sinalizam que:

algum estresse é importante para a realização de qualquer atividade e que sua total ausência, assim como seu excesso, podem ser prejudiciais à saúde. Entretanto, o prolongamento de situações de estresse pode repercutir num quadro patológico, originando distúrbios transitórios ou mesmo doenças graves, como o estresse ocupacional.

Desse modo, cada pessoa pode considerar o estresse sob um prisma distinto. Para algumas pode ser um agente desmotivador, ao passo que para outras pode assumir conotação inversa. Em consonância, Garbarino, Chiorri e Magnavita (2014), Kaur, Chodagiri e 
Reddi (2013) defendem que o estresse pode estar relacionado tanto à vida pessoal como à vida social dos indivíduos, manifestando-se de maneira distinta em cada indivíduo.

Situações de estresse são recorrentes em questões pessoais e sociais, contudo também podem ser verificadas no ambiente de trabalho. Pereira (2002, p. 46) salienta que "o estresse pode acometer qualquer pessoa e, quando o agente desencadeador se refere à atividade desempenhada, o mais correto seria a designação de estresse ocupacional".

O estresse ocupacional está diretamente relacionado ao esforço despendido na adaptação a ambientes inadequados, ou seja, ao desgaste físico e mental ocasionado pelo desempenho de atividades na presença de condições precárias (SANTOS; CUBAS, 2012; ZANELLI, 2010). Assim, quando o cenário organizacional é interpretado de maneira deficiente pelo colaborador pode conduzir a sua ineficiência.

Nesse sentido, Alexopoulos et al. (2014) afirmam que os níveis de estresse têm efeito negativo profundo tanto na satisfação dos indivíduos no trabalho como na qualidade de vida. Dependendo da intensidade dessas condições de desgaste, o estresse se manifesta e acaba impactando diretamente a saúde das pessoas (WALVEKAR; AMBEKAR; DEVARANAVADAGI, 2015). Dessa forma, níveis elevados, além de causarem a diminuição da produtividade individual de cada colaborador, podem ocasionar doenças de ordem física e psicológica.

Os sintomas físicos e mentais de estresse podem se manifestar tanto em nível individual como também no organizacional (PAIVA et al., 2013). Consonante essa afirmação, Jex et al. (2012) dispõem que o estresse ocupacional prejudica a seara financeira das organizações, tendo em vista a ocorrência de dispêndios de recursos relacionados, por exemplo, com tratamento de doenças dos funcionários. Assim, é possível inferir que, por meio da interferência no desempenho individual das pessoas, o estresse ocupacional afeta o alcance dos objetivos das organizações públicas e privadas.

Alguns autores têm conceituado os eventos ou fatores que ocasionam o estresse como estressores. Para Marras e Veloso (2012), agentes estressores são fatores ou elementos que despertam nos indivíduos a obrigatoriedade de resposta por entenderem que 
esse fato é consciente ou inconscientemente ameaçador. Da mesma forma, Carayon, Smith e Haims (1999) defendem que estressores estão ligados à organização do trabalho, como carga de trabalho excessiva, condições insalubres, falta de treinamento e de orientação, entre outras.

Já para Bianchi (2009, p. 1056), “estressor pode ser entendido como qualquer evento, interno ou externo, e que leve o indivíduo a uma avaliação cognitiva desse evento". Desse modo, esse conceito está diretamente relacionado às causas que propiciam situações em que o estresse se manifesta. Pereira (2002) elenca três tipos de estressores, conforme descrito no Quadro 1.

\section{Quadro 1: Tipos de estressores}

\begin{tabular}{|l|l|}
\hline Estressor & Definição \\
\hline Físicos & $\begin{array}{l}\text { São provenientes do ambiente externo, tais como ruídos, } \\
\text { frio ou calor intenso e/ou persistente, acidentes, fome, } \\
\text { dor; ou ainda os que interferem predominantemente no } \\
\text { corpo do indivíduo, como excesso de exercícios físicos, } \\
\text { alimentação pesada, utilização de drogas etc. } \\
\text { São avaliados como ameaçadores à integridade do indi- } \\
\text { víduo ou a seu patrimônio (físico ou psicossocial), tais } \\
\text { como iminência ou a vivência de um assalto, envolvimen- } \\
\text { to em uma discussão, seleção a um emprego, provas etc. } \\
\text { Aqueles sentimentos como perda, medo e ira, entre } \\
\text { outros, ou acontecimentos como casamento, divórcio, } \\
\text { mudanças (de casa, escola, cidade etc.), em que o compo- } \\
\text { nente afetivo se faz mais proeminente. }\end{array}$ \\
$\begin{array}{l}\text { Emocio- } \\
\text { nais }\end{array}$
\end{tabular}

Fonte: Adaptado de Pereira (2002).

Percebe-se então que a exaustão provocada pelo estresse ocupacional pode ser tanto física como relacionada a aspectos intangíveis, como sentimentos, valores e relações de trabalho. Contudo, por meio da identificação e intervenção desses fatores de risco, o estresse e problemas de saúde no local de trabalho podem ser minimizados (WALVEKAR; AMBEKAR; DEVARANAVADAGI, 2015). Marras e Veloso (2012, p. 113) mencionam alguns tópicos relevantes para o processo de mapeamento do estresse: 
Intensidade do processo: as consequências do estresse variam proporcionalmente a intensidade;

Tempo de permanência do agente estressor: quanto maior o tempo, maior o impacto do estresse no indivíduo;

Capacidades, condição de saúde e características individuais: o indivíduo com bom estado de saúde reduzirá a capacidade do estresse em desenvolver doenças;

Resultados das ações dos indivíduos sobre os agentes estressores: capacidade do indivíduo em lidar com as situações de forma satisfatória.

Observa-se assim que um dos complicadores do estresse ocupacional é o período em que o indivíduo fica exposto a essas condições. Em relação a isso, entre as atividades mais propensas a esse estresse estão aquelas relacionadas à segurança pública. Nesse cenário se inserem os policiais militares, que absorvem sentimentos muitas vezes desagradáveis e desmotivadores. Segundo Kaur Chodagiri e Reddi (2013), Almale et al. (2014) e Weltman et al. (2014), essas pessoas têm que enfrentar situações potencialmente perigosas que podem ocasionar danos físicos e mentais, possibilitando até mesmo o óbito no desempenho da função.

Nessas atividades, o estresse ocupacional é comum em praticamente todos os que fazem parte da organização e em vários níveis de hierarquia (ALMALE et al., 2014). Em estudos realizados com policiais dos Estados Unidos da América, evidenciou-se que o estresse não só pode diminuir o desempenho como também produzir resultados negativos à saúde, lesões psicológicas e conflitos familiares (SELOKAR et al., 2011; WELTMAN et al., 2014). Torna-se ululante que a manutenção da segurança pública inúmeras vezes é propensa a situações conflituosas e danosas aos agentes públicos. Todavia, as ameaças físicas e psicológicas são inerentes ao trabalho policial, sendo relativamente difícil reduzir a sua ocorrência (MA et al., 2015).

À medida que essas situações se tornam recorrentes, o estresse acumulado pode prejudicar tanto a vida pessoal como a social dos policiais militares.

O estresse, relacionado ao trabalho, é definido como situações em que a pessoa percebe seu ambiente laboral como ameaçador de suas neces- 
sidades de realização profissional, ou de sua saúde física ou mental, prejudicando a interação da pessoa com os outros e com o ambiente de trabalho, na medida em que este ambiente contém demandas excessivas a ela, ou que ela não dispõe de recursos adequados para enfrentar tais situações. (MENDOZA; MEDEIRO; COSTA, 2007, p. 95)

Para analisar os efeitos do estresse, é necessário mensurar suas características com as do meio em que estão inseridas as pessoas. Com essa finalidade, Paschoal e Tamayo (2004) desenvolveram e validaram a Escala de Estresse no Trabalho (EET), a qual apresenta ao indivíduo uma lista de estressores que devem ser avaliados numa escala de frequência; e uma lista de reações que devem ser analisadas de forma independente dos estressores.

Nesse instrumento foram utilizados 23 itens que formam um fator geral, sendo adaptável a inúmeros ambientes de trabalho. Conforme Martins (2011, p. 79) esses itens são “analisados através de uma escala de concordância do tipo likert de 5 pontos, cada item englobando um tipo de estressor e um tipo de reação a esse estressor". Desse modo, uma das grandes vantagens dessa escala é a sua adaptabilidade a diferentes contextos, englobando organizações tanto do âmbito público como do privado.

É possível inferir que a análise do estresse ocupacional é uma atividade complexa, a julgar pela quantidade de fatores a serem considerados antes de implementar medidas preventivas ou corretivas. Em determinados casos, a recorrência de situações de estresse ocupacional elevado propicia o desenvolvimento de problemas físicos e mentais mais graves. Isso está de acordo com Monteiro, Dalagasperina e Quadros (2012, p. 20), os quais afirmam que “além do Estresse ocupacional, podem também aparecer outras doenças ocupacionais causadas por sua recorrência e permanência, entre as quais se destaca a Síndrome de Burnout".

\section{MÉTodo}

A presente pesquisa é de natureza descritiva, que, segundo Gil (2007, p. 42), tem “como objetivo primordial a descrição das características de determinada população ou fenômeno ou, então, o estabelecimento de relação entre variáveis". Esse tipo de pesquisa 
se evidencia também pelas técnicas de coletas de dados, entre as quais se inclui o questionário.

Por sua vez, a abordagem da pesquisa é quantitativa. Lopes et al. (2008) a classificam assim em virtude de ela permitir identificar características populacionais que podem ser mensuradas por meio da utilização de técnicas estatísticas. Diehl e Tatim (2004) justificam-na pelo uso da quantificação tanto na coleta quanto no tratamento das informações por meio de técnicas estatísticas, envolvendo média e desvio-padrão. O objetivo desse modelo de pesquisa é garantir resultados e evitar distorções de análise e de interpretação, assegurando uma margem maior de segurança quanto às inferências.

O tipo de pesquisa utilizado é a survey, que para Babbie (2001, p. 96) "permite enunciados descritivos sobre alguma população, isto é, descobrir a distribuição de certos traços e atributos. O pesquisador não se preocupa com o porquê da distribuição existir, mas como que ela é". Em consonância com esse autor, a pesquisa survey demonstrou atender ao objetivo da pesquisa apresentando o cenário atual da Brigada Militar no Estado do Rio Grande do Sul, no que se refere ao estresse ocupacional.

Para o cálculo da amostra do estudo foi adotada a fórmula estatística para população finita, com base em Lopes et al. (2008, p. 94), segundo a equação:

$$
n=\frac{Z_{\alpha / 2}^{2} \cdot \hat{p} \cdot \hat{\mathrm{q}} \cdot \mathrm{N}}{e^{2}(N-1)+Z_{\alpha / 2}^{2} \cdot \hat{p} \cdot \hat{\mathrm{q}}}
$$

em que:

$\mathrm{Z} \alpha / 2$ = valor padrão de $\mathrm{Z}$ (distribuição normal) para um nível de confiança de $95 \%=1,96$

$\mathrm{p}^{\wedge}=$ percentual estimado $=0,5$

$\mathrm{q}^{\wedge}=$ complemento de $\hat{\mathrm{q}}=1-\hat{p}=0,5$

$\mathrm{e}=$ erro amostral $=0,05$

$\alpha=$ nível de significância $=0,05$

Por meio dessa fórmula, considerando-se um erro amostral de $5 \%$ e um nível de $95 \%$ de confiança dos dados numa população de 33.650 policiais militares, o tamanho da amostra é de, no mínimo, 381 indivíduos. No entanto, foi possível constituir uma amostra de 
519 policiais militares, que trabalham efetivamente em 97 municípios do estado do Rio Grande do Sul.

A escolha dos policiais militares ocorreu por meio de amostragem não probabilística, uma vez que a inclusão de cada um foi de acordo com a disponibilidade no dia e horário determinado pela Brigada Militar para a aplicação. Assim, utilizou-se uma amostragem por conveniência para a escolha dos policiais que participaram da pesquisa, mesmo que tenha sido calculada uma amostra mínima, recorrendo a um método probabilístico.

O instrumento utilizado para coletar os dados sobre o estresse ocupacional foi a Escala de Estresse no Trabalho (EET), composta por 23 itens e validada por Paschoal e Tamayo (2004). Essa escala foi elaborada a partir da análise de literatura sobre estressores organizacionais de natureza psicossocial e sobre reações psicológicas ao estresse ocupacional. Cada item aborda tanto um estressor quanto uma reação a ele. A decisão de se conjugarem estressor e reação se deve à convicção da percepção do impacto no ambiente de trabalho. Para análise foram padronizados os resultados das médias obtidas na escala EET, classificando-as em três categorias: baixo (média de 0 a $33,33 \%$ ), médio (média de $33,34 \%$ a $66,66 \%$ ) e alto (média de $66,67 \%$ a $100 \%$ ) estresse ocupacional.

Após a coleta, os dados foram organizados em uma planilha eletrônica, no programa Microsoft Office Excel, criando, assim, um banco de dados para, posteriormente, ser analisado eletronicamente com o auxílio do programa Statistical Package for Social Sciences (SPSS).

Por fim, com relação aos aspectos éticos, a pesquisa foi estruturada em conformidade com a Resolução no 196/1996 do Conselho Nacional de Saúde, bem como registrada no Gabinete de Projetos (GAP) do Centro de Ciências Sociais e Humanas (CCSH) da Universidade Federal de Santa Maria (UFSM) sob o número de projeto 036461. Finalizada essa etapa, o projeto foi destinado ao Comando Geral da Brigada Militar do Estado para registro, avaliação e liberação. Posteriormente, o referido estudo foi registrado no Sistema Nacional de Ética em Pesquisa (SISNEP) sob o certificado de apresentação para apreciação ética (CAAE) de nº 31304914.4.0000.5346. 


\section{ANÁLISE E DISCUSSÃo DOS DADOS}

No decorrer deste tópico serão demonstrados os resultados obtidos nesta pesquisa, por meio da caracterização do perfil dos pesquisados e da análise estatística sobre o nível de estresse ocupacional dos participantes.

\subsection{Caracterização do perfil dos participantes}

Participou da pesquisa um total de 519 policiais militares do estado do Rio Grande do Sul. A síntese dos principais dados pessoais e ocupacionais dos pesquisados pode ser visualizada na Tabela 1.

Tabela 1: Principais dados pessoais e ocupacionais do perfil dos pesquisados

\begin{tabular}{|c|c|c|}
\hline Dados & Resultados & \\
\hline \multirow{6}{*}{ 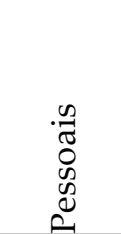 } & Gênero & Masculino $(83,43 \%)$ \\
\hline & Faixa de idade & 31 anos ou mais $(66,47 \%)$ \\
\hline & Estado civil & Casado $(72,45 \%)$ \\
\hline & Filhos & Possui filhos $(67,63 \%)$ \\
\hline & Número de filhos & Um filho $(42,45 \%)$ \\
\hline & Escolaridade & Ensino Médio (59,15\%) \\
\hline \multirow{5}{*}{ 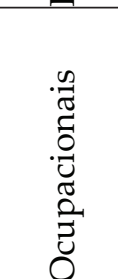 } & Tempo de atuação & 21 a 30 anos $(31,98 \%)$ \\
\hline & Posto & Soldado $(58,76 \%)$ \\
\hline & Atividade & Externa $(42,58 \%)$ \\
\hline & Renda & 1 a 3 salários mínimos \\
\hline & $\begin{array}{l}\text { Grau de responsabilidade } \\
\text { pela manutenção financei- } \\
\text { ra da família }\end{array}$ & $\begin{array}{l}\text { Divide igualmente as respon- } \\
\text { sabilidades com outra pessoa } \\
(35,45 \%)\end{array}$ \\
\hline
\end{tabular}

Fonte: Dados da pesquisa (2015).

Pode-se afirmar que a amostra do presente estudo é predominantemente do gênero masculino, com idade de 31 anos ou mais, casados, com apenas um filho e, quanto à escolaridade, a maioria detém ensino médio completo. Já quanto aos dados ocupacionais, é possível perceber que o perfil da amostra do presente estudo é predominantemente constituído por policiais militares com atuação na Brigada Militar entre 21 a 30 anos (31,98\%), graduados no posto de soldado $(58,76 \%)$, exercem atividades externas $(42,58 \%)$, possuem renda entre 1 a 3 salários mínimos (52,41\%) e dividem igualmente a responsabilidade pela manutenção financeira da família com outra pessoa $(35,45 \%)$. 


\subsection{Nível de estresse ocupacional}

Analisou-se o estresse ocupacional a partir das 23 questões que compõem a Escala de Estresse no Trabalho (EET) de Paschoal e Tamayo (2004). Para isso, padronizaram-se os resultados das médias obtidas na escala classificando-as em três categorias: baixo (média de 0 a 33,33\%), médio (média de 33,34\% a 66,66\%) e alto (média de $66,67 \%$ a $100 \%$ ) estresse ocupacional. O percentual geral do nível de estresse ocupacional pode ser observado na Figura 1.

Figura 1: Percentual geral do nível de estresse ocupacional

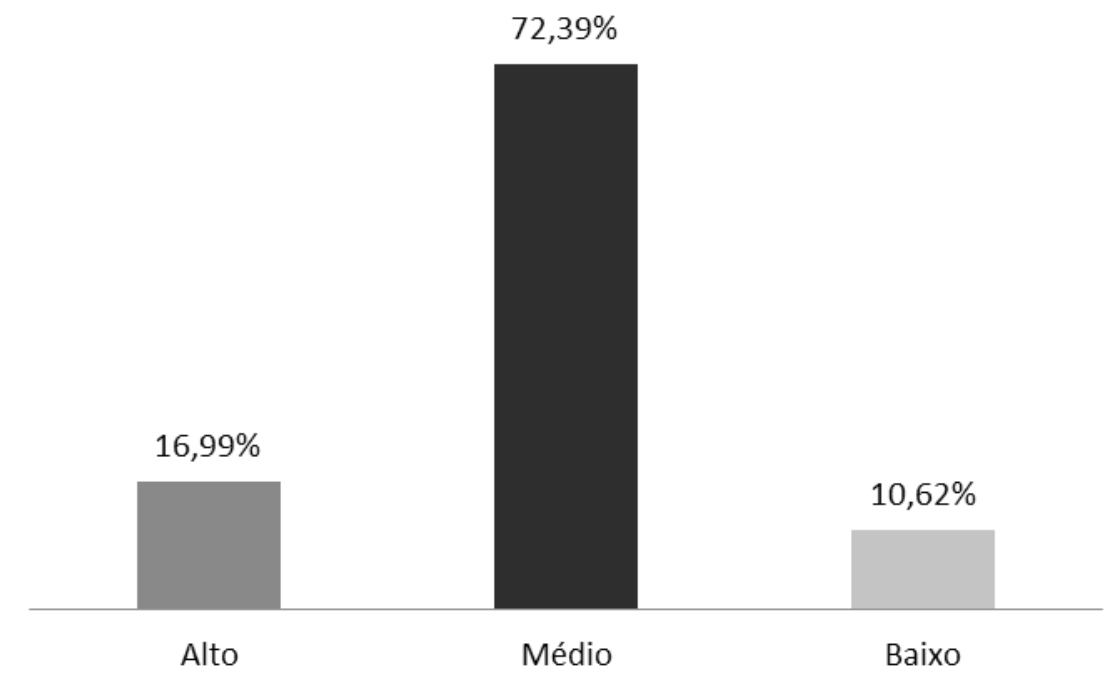

Fonte: Dados da pesquisa (2015).

Ao verificar a Figura 1, constatou-se que a maioria (72,39\%) dos participantes da pesquisa apresentou nível médio de estresse ocupacional, ao passo que $16,99 \%$ demonstraram alto nível e 10,62\%, baixo nível. Sampaio e Galasso (2012) destacam que autores como Sauter et al., em 1998, mencionavam que, nos Estados Unidos e na Europa, o estresse já representava uma das principais causas de incapacitação para o trabalho. Casos como de doenças cardiovasculares, hipertensão, úlcera, doenças inflamatórias intestinais e distúrbios osteomusculares relacionados ao trabalho (DORT) representam, no Brasil, os principais motivos de pedidos de afastamento do trabalho ao sistema previdenciário. 
Evidencia-se por meio dos resultados a necessidade de ações pelo Comando da Brigada Militar que contribuam para a diminuição do nível médio de estresse, pois conforme salientam Limongi-França e Rodrigues (2012), as reações ao estresse são necessárias para a sobrevivência, porém podem se tornar prejudiciais ao indivíduo.

As consequências que o estresse ocasiona atingem os três níveis: individual, grupal e organizacional. No individual, os registros apontam para: queda da eficiência, ausências repetidas, insegurança nas decisões, protelação na tomada de decisão, sobrecarga voluntária de trabalho, uso abusivo de medicamentos, irritabilidade constante, explosão emocional, grande nível de tensão, sentimento de frustração, sentimentos de onipotência, desconfiança e agravamento de doenças. Limongi-França e Rodrigues (2012) explicam ainda que tais indicativos desencadeiam questões relacionadas ao grupo, tais como: competição não saudável, politicagem, comportamento hostil, discussões inúteis, pouca contribuição no trabalho, trabalho isolado dos demais membros, não compartilhamento de problemas, alto nível de insegurança e grande dependência do líder. No nível organizacional ocorrem prejuízos como greves, atrasos constantes nos prazos, absenteísmo, alta rotatividade de funcionários, altas taxas de doenças, baixo nível de esforço e vínculos empobrecidos.

No caso do policial militar, existem outros fatores como trabalho noturno, trabalho em turnos e exposição a altas temperaturas que contribuem para comprometer a saúde, desde a fadiga crônica até a incapacidade laboral. Os autores alertam que para esses casos fazem-se necessárias intervenções no ambiente físico a fim de minimizar as doenças ocupacionais.

Três recursos são estabelecidos por Limongi-França e Rodrigues (2012) para minimizar o estresse: físicos, psíquicos e sociais. Quanto aos recursos físicos são abordadas técnicas como a de relaxamento, alimentação adequada, exercício físico regular, repouso, lazer e diversão. Quanto aos recursos psíquicos, os autores sugerem métodos psicoterapêuticos, processos que favoreçam o autoconhecimento, planejamento do tempo livre com atividades prazerosas, avaliação periódica da qualidade de vida, reavaliação do limite de tolerância e exigência, busca de convivência menos conflituosa com pares e grupos. E, por fim, nos recursos sociais são mencionadas questões relacionadas ao trabalho, tais como: revisão e redimensionamento 
das formas de organização do trabalho, abrangendo mudanças no poder, abolindo o trabalho coercitivo e repetitivo; aperfeiçoamento dos métodos de trabalho, procurando aumentar a participação e a motivação do grupo; melhoria das condições socioeconômicas; e investimento na formação pessoal e profissional. Além desses recursos, para os autores autora é necessário investir no planejamento econômico, social e de saúde.

Paschoal e Tamayo (2004) alertam que estudos têm abordado os efeitos negativos do estresse, o qual atinge a saúde e o bem-estar do indivíduo, além da efetividade organizacional. Sendo assim, é importante utilizar uma ferramenta de diagnóstico a fim de identificar e orientar ações que visem à qualidade de vida dos colaboradores. Na Tabela 2 observam-se os itens que compõem a Escala de Estresse no Trabalho Ocupacional e a respectiva estatística descritiva (média e desvio-padrão).

Analisando as médias encontradas na Tabela 2 em cada item da Escala de Estresse no Trabalho, de Paschoal e Tamayo (2004), identificaram-se os cinco itens com maior média, ou seja, os estressores que contribuem significativamente para o resultado do nível médio de estresse dos policiais militares pesquisados. Destaca-se que a maioria está se sentindo incomodada com a deficiência nos treinamentos para capacitação profissional (item 13 - média 3,51); está irritada com a discriminação/favoritismo no ambiente de trabalho (item 12 - média 3,40); sente-se angustiada com as poucas perspectivas de crescimento na carreira (item 16 - média 3,37); fica irritada por ser pouco valorizada por seus superiores (item 15 - média 3,04); e por fim encontra-se irritada com a deficiência na divulgação de informações sobre as decisões organizacionais (item 5 - média 3,00).

Freitas (2013), ao pesquisar o estresse ocupacional em policiais rodoviários federais no estado do Rio Grande do Sul, utilizando a mesma escala que o presente estudo, identificou, entre outros itens, também 13, 5 e 12 como estressores, fazendo parte das cinco maiores médias encontradas $(3,03 ; 2,82$; e 2,65; respectivamente). Isso ratifica que no ambiente de trabalho de policiais as questões relacionadas à deficiência nos treinamentos de capacitação profissional, à deficiência na divulgação de informações sobre as decisões organizacionais e à discriminação/favoritismo no ambiente de trabalho podem ser realmente considerados estressores. 
Tabela 2: Estatística descritiva dos itens da Escala de Estresse no Trabalho

\begin{tabular}{|c|c|c|}
\hline Itens da Escala de Estresse no Trabalho (EET) & Média & $\begin{array}{l}\text { Desvio- } \\
\text {-padrão }\end{array}$ \\
\hline $\begin{array}{l}\text { 13. Tenho me sentido incomodado com a deficiência nos treina- } \\
\text { mentos para capacitação profissional. }\end{array}$ & 3,51 & 1,27 \\
\hline $\begin{array}{l}\text { 12. Fico irritado com discriminação/favoritismo no meu ambien- } \\
\text { te de trabalho. }\end{array}$ & 3,40 & 1,36 \\
\hline $\begin{array}{l}\text { 16. As poucas perspectivas de crescimento na carreira têm me } \\
\text { deixado angustiado. }\end{array}$ & 3,37 & 1,32 \\
\hline 15. Fico irritado por ser pouco valorizado por meus superiores. & 3,04 & 1,32 \\
\hline $\begin{array}{l}\text { 5. Sinto-me irritado com a deficiência na divulgação de informa- } \\
\text { ções sobre decisões organizacionais. }\end{array}$ & 3,00 & 1,16 \\
\hline $\begin{array}{l}\text { 1. A forma como as tarefas são distribuídas em minha área tem } \\
\text { me deixado nervoso. }\end{array}$ & 2,90 & 1,04 \\
\hline $\begin{array}{l}\text { 3. A falta de autonomia na execução do meu trabalho tem sido } \\
\text { desgastante. }\end{array}$ & 2,86 & 1,13 \\
\hline 2. O tipo de controle existente em meu trabalho me irrita. & 2,79 & 1,09 \\
\hline $\begin{array}{l}\text { 10. Fico de mau humor por ter que trabalhar durante muitas } \\
\text { horas seguidas. }\end{array}$ & 2,76 & 1,30 \\
\hline $\begin{array}{l}\text { 8. Sinto-me incomodado por meu superior tratar-me mal na } \\
\text { frente de colegas de trabalho. }\end{array}$ & 2,61 & 1,42 \\
\hline $\begin{array}{l}\text { 17. Tenho me sentido incomodado por trabalhar em tarefas abai- } \\
\text { xo do meu nível de habilidade. }\end{array}$ & 2,52 & 1,20 \\
\hline $\begin{array}{l}\text { 6. Sinto-me incomodado com a falta de informações sobre mi- } \\
\text { nhas tarefas no trabalho. }\end{array}$ & 2,51 & 1,10 \\
\hline $\begin{array}{l}\text { 21. Sinto-me irritado por meu superior encobrir meu trabalho } \\
\text { bem feito diante de outras pessoas. }\end{array}$ & 2,50 & 1,20 \\
\hline $\begin{array}{l}\text { 4. Tenho me sentido incomodado com a falta de confiança de } \\
\text { meu superior sobre o meu trabalho. }\end{array}$ & 2,44 & 1,23 \\
\hline $\begin{array}{l}\text { 9. Sinto-me incomodado por ter que realizar tarefas que estão } \\
\text { além de minha capacidade. }\end{array}$ & 2,42 & 1,19 \\
\hline $\begin{array}{l}\text { 11. Sinto-me incomodado com a comunicação existente entre } \\
\text { mim e meu superior. }\end{array}$ & 2,41 & 1,15 \\
\hline $\begin{array}{l}\text { 19. A falta de compreensão sobre quais são minhas responsabili- } \\
\text { dades neste trabalho tem causado irritação. }\end{array}$ & 2,40 & 1,05 \\
\hline $\begin{array}{l}\text { 20. Tenho estado nervoso por meu superior me dar ordens } \\
\text { contraditórias. }\end{array}$ & 2,38 & 1,11 \\
\hline $\begin{array}{l}\text { 22. O tempo insuficiente para realizar meu volume de trabalho } \\
\text { deixa-me nervoso. }\end{array}$ & 2,33 & 1,05 \\
\hline $\begin{array}{l}\text { 18. A competição no meu ambiente de trabalho tem me deixado } \\
\text { de mau humor. }\end{array}$ & 2,32 & 1,07 \\
\hline $\begin{array}{l}\text { 23. Fico incomodado por meu superior evitar me incumbir de } \\
\text { responsabilidades importantes. }\end{array}$ & 2,29 & 1,04 \\
\hline 14. Fico de mau humor por me sentir isolado na organização. & 2,19 & 1,10 \\
\hline $\begin{array}{l}\text { 7. A falta de comunicação entre mim e meus colegas de trabalho } \\
\text { deixa-me irritado. }\end{array}$ & 2,18 & 1,03 \\
\hline
\end{tabular}

Fonte: Dados da pesquisa (2015). 
Para Kompier e Kristensen (2003), alguns trabalhos são estressantes por natureza e pode não ser muito realista reduzir ou eliminar os fatores de risco. Nessa circunstância faz sentido ensinar aos empregados como lidar com as condições necessárias do trabalho. A questão principal é ser capaz de diferenciar entre as condições necessárias e as que podem ser mudadas. Para isso, é interessante o uso de diagnóstico para identificar os fatores de risco, condição indispensável para elaborar e manter programas de prevenção.

Esses autores aconselham ainda que os pesquisadores da área de estresse não devem lidar apenas com resultados considerados soft, como motivação, satisfação, queixa de saúde, mas também incluir variáveis de resultados hard, como produtividade e absenteísmo por doença. Visando a aumentar o impacto da prevenção, segundo Kompier e Kristensen (2003), deve-se focar aspectos como qualidade de produtos e serviços, absenteísmo, produtividade, aumento de competitividade, buscando uma abordagem multidisciplinar, em vez de uma monodisciplinar. Os objetivos devem ser claros desde o início e mensurados de maneira válida.

Já ao estudar estresse e coping em trabalhadores de enfermagem, Benetti (2013) identificou os itens 12, 15, 16 e 5 como sendo os estressores com maiores médias $(2,96 ; 2,58 ; 2,57$; e 2,50; respectivamente). Esses índices indicam que questões como discriminação/favoritismo no ambiente de trabalho; pouca valorização por parte dos superiores; poucas perspectivas de crescimento na carreira; e deficiência na divulgação de informações sobre as decisões organizacionais; são questões emergentes que merecem atenção dos gestores.

Ainda na Tabela 2, estão demonstrados os cinco estressores com a menor média, isto é, aqueles referentes a situações que pouco interferem no nível de estresse encontrado nos policiais pesquisados: o tempo insuficiente para realizar meu volume de trabalho deixa-me nervoso (item 22 - média 2,33); a competição no meu ambiente de trabalho tem me deixado de mau humor (item 18 - média 2,32); fico incomodado por meu superior evitar me incumbir de responsabilidades importantes (item 23 - média 2,29); fico de mau humor por me sentir isolado na organização (item 14 - média 2,19); e por fim a falta de comunicação entre mim e meus colegas de trabalho deixa-me irritado (item 7 - média 2,18). 
No caso dos policiais rodoviários pesquisados por Freitas (2013), os estressores com menores médias que coincidem com os encontrados na presente pesquisa foram os itens 23 e 14, com médias de 1,92 e 1,88, respectivamente. Questões como o superior evitar incumbir responsabilidades importantes e se sentir isolado na organização são aspectos pouco frequentes no ambiente de trabalho, portanto não necessitam de intervenções institucionais. Nos achados de Benetti (2013), ao pesquisar enfermeiros, os estressores com as menores médias também foram os itens 23 e 14, com médias de 2,08 e 2,01, respectivamente, que vão ao encontro dos resultados de Freitas (2013) e da presente pesquisa.

A importância em identificar e mensurar os estressores se dá pelo fato de que a simples presença de um evento definido como provável estressor não confirma que ele seja assim classificado. $\mathrm{O}$ indivíduo é que avalia e determina se realmente o evento é estressor. Sendo assim, para Lazarus e Folkman (1984) os fatores cognitivos possuem grande importância nesse processo de estímulo e resposta.

Outra medida descritiva que merece atenção são os valores encontrados para os desvios-padrão apresentados na Tabela 2, que permitem inferir que os itens da escala obtiveram uma distribuição homogênea entre os pesquisados em relação às respostas.

A partir do exposto, verifica-se que os policiais pesquisados apresentam nível médio de estresse ocupacional, sendo identificados os estressores que desencadeiam tal índice. Dessa forma, a pesquisa contribui para as futuras decisões organizacionais na solução das evidências constatadas.

Diante da apresentação dos resultados obtidos e discutidos com a literatura sobre o tema estresse ocupacional, propõem-se algumas estratégias que podem auxiliar na adequação de tais resultados ao contexto organizacional pesquisado:

- Proporcionar convênios da Brigada Militar com outros órgãos públicos para execução de um processo permanente de discussão, atualização e prevenção a respeito dos temas saúde do trabalhador e qualidade de vida;

- Pesquisar as causas e motivos que desencadeiam o estresse ocupacional; 
- Implantar programas que visem a minimizar as causas e consequências do estresse ocupacional;

- Realizar monitoramento constante da saúde dos policiais, por profissionais da área da saúde como psicólogos e psiquiatras, a fim de desenvolver ações preventivas quando necessário. Sugere-se que esses profissionais não sejam colegas da instituição para que não ocorram constrangimentos e receios ao relatar os problemas;

- Monitorar as estatísticas de afastamento dos policiais militares do trabalho por motivos relacionados à saúde do trabalhador, em especial ao estresse ocupacional;

- Aperfeiçoar o processo de formação dos policiais militares a fim de minimizar o estresse por meio do desenvolvimento de habilidades de enfrentamento.

\subsection{Limitações}

Aponta-se como uma das limitações deste estudo a dificuldade em comparar os achados obtidos com os de outras pesquisas sobre tais temáticas, especificamente com policiais militares. Essa carência se dá principalmente devido ao fato de a coleta dos dados ter ocorrido em apenas um estado do Brasil, de modo que a generalização dos resultados é restrita à realidade do Rio Grande do Sul. Sugere-se, para estudos futuros, replicar esta pesquisa com uma amostra nas diversas regiões brasileiras, ou até mesmo em outros países, a fim de realizar análises comparativas.

Outra limitação relevante é a utilização de apenas da abordagem quantitativa na pesquisa. Desse modo, aconselha-se que estudos futuros adotem as abordagens qualitativa e quantitativa de forma simultânea. A realização de entrevistas com um segmento dos participantes pode ser utilizada como uma estratégia qualitativa no intuito de identificar possíveis peculiaridades que não foram percebidas no presente estudo. Sugere-se também a realização desta mesma pesquisa sob um viés longitudinal, pois possibilitará acompanhar o desenvolvimento e comparar a mudança nos níveis de estresse ocupacional. 


\section{CONSIDERAÇõES FINAIS}

Constatou-se que os indivíduos pesquisados apresentam, em sua maioria, nível médio de estresse ocupacional. Esse resultado requer zelo, visto que caso não sejam feitas intervenções visando a reverter esse quadro, corre-se o risco de tal índice intensificar-se, atingindo alto nível de estresse.

Os estressores com maiores médias, isto é, que contribuem significativamente para o resultado do nível médio de estresse dos policiais militares pesquisados e que merecem atenção estão relacionados a: deficiência nos treinamentos para capacitação profissional; discriminação/favoritismo no ambiente de trabalho; poucas perspectivas de crescimento na carreira; pouca valorização pelos superiores; e deficiência na divulgação de informações sobre decisões organizacionais.

Logo, sugerem-se algumas estratégias com vistas a auxiliar na adequação desses resultados no contexto organizacional estudado: a) elaborar um plano de carreira baseado nos conhecimentos, habilidades e atitudes, visando à valorização profissional e consequentemente da imagem da profissão; b) implementar ações de treinamento e desenvolvimento adequados às necessidades da Brigada Militar e realizar constante avaliação dos resultados; c) implantar programa efetivo de comunicação interna, utilizando ferramentas como correio eletrônico, buscando agilizar o trâmite das informações; e d) proporcionar, aos policiais com cargo de liderança, treinamento constante para melhorar a gestão de pessoas.

Já os estressores com as menores médias, isto é, situações que pouco interferem no nível de estresse encontrado nos policiais pesquisados, são: tempo suficiente para realizar o volume de trabalho; não há competição no ambiente de trabalho; o superior evita incumbir responsabilidades importantes; não se sente isolado na organização; e a comunicação entre os colegas de trabalho.

Por fim, salienta-se que as conclusões e limitações encontradas nesta pesquisa poderão ensejar a construção de novos estudos sobre a temática e o público analisado. Essas investigações se justificam em virtude das lacunas provenientes do reduzido número de estudos na área. Espera-se que a realização desta pesquisa, além de contribuir para estudos futuros, possa também servir de reflexão 
para a gestão da Brigada Militar do Estado do Rio Grande do Sul, contribuindo para a efetiva saúde dos servidores e consequente qualidade de vida da equipe e de seus familiares.

\section{REFERÊNCIAS}

ABREU, K. L. de et al. Estresse ocupacional e Síndrome de Burnout no exercício profissional da psicologia. Psicologia: Ciência e Profissão, Brasília, v. 22, n. 2, p. 22-9, 2002. Disponível em: <http://www.scielo.br/scielo.php?script=sci_arttext\&pid=S1414-98932002000200004>. Acesso em: 12 jul. 2014.

ALEXOPOULOS, E. C. et al. Exploring Stress Levels, Job Satisfaction, and Quality of Life in a Sample of Police Officers in Greece. Safety and Health at Work, Korea v. 5, n. 4, p. 2105, 2014. Disponível em: <http://www.e-shaw.net/article/S2093-7911(14)00052-3/pdf>. Acesso em: 15 jan. 2015.

ALMALE, B. D. et al. An epidemiologic study of occupational stress factors in Mumbai police personnel. Indian Journal of Occupational and Environmental Medicine, India v. 18, n. 3, p. 109-112, 2014. Disponível em: <https://www.ncbi.nlm.nih.gov/pmc/articles/PMC4292194/>. Acesso em: 05 jan. 2015.

BABBIE, E. Métodos de Pesquisas de Survey. Belo Horizonte: UFMG, 2001.

BENETTI, E. R. R.al. Estresse e Coping em trabalhadores de enfermagem de um hospital privado. 115 f. Dissertação (Mestrado em Enfermagem) - Universidade Federal de Santa Maria, Santa Maria, 2013. Disponível em: < http://cascavel.ufsm.br/tede//tde_arquivos/33/ TDE-2014-02-24T140442Z-4851/Publico/BENETTI,\%20ELIANE\%20RAQUEL\%20RIETH. pdfpdf $>$. Acesso em: 22 out. 2013.

BIANCHI, E. R. F. Conceito de Stress: evolução histórica. Nursing, São Paulov. 4, n. 39, p. 16-9, 2001. Disponível em: <http://bases.bireme.br/cgi-bin/wxislind.exe/iah/online/?IsisScript= $\mathrm{iah} / \mathrm{iah} . \mathrm{xis} \& \mathrm{src}=$ google\&base=BDENF\&lang $=$ p\&nextAction=lnk\&exprSearch=11088\&indexSe arch=ID>. Acesso em: 15 jan. 2015.

. Escala Bianchi de Stress. Revista da Escola de Enfermagem USP, São Paulov. 43, n. 2, p. 1055-1062, 2009. Disponível em: < http://www.scielo.br/pdf/reeusp/v43nspe/en_a09v43ns. pdf $>62342009000500009$. Acesso em: 14 maio 2013.

BONEZ, A.; DAL MORO, E.; SEHNEM, S. B. Saúde mental de agentes penitenciários de um presídio catarinense. Revista Psicologia Argumento, Curitiba, v. 31, n. 74, p. 507-517, 2013. Disponível em: < http://www2.pucpr.br/reol/pb/index.php/pa?dd1=12241\&dd99=view\&dd98=pb pb>. Acesso em: 20 jan. 2014.

BRASIL. Organização Pan-Americana da Saúde no Brasil. Doenças relacionadas ao trabalho: manual de procedimentos para os serviços de saúde. Brasília: Ministério da Saúde, 2001. Disponível em: < http://bvsms.saude.gov.br/bvs/publicacoes/doencas_relacionadas_trabalho1. pdf pdf $>$. Acesso em: 30 set. 2013.

CAMELO, S. H. H.; ANGERAMI, E. L. S. Riscos psicossociais no Trabalho que podem levar ao estresse: uma análise da literatura. Revista Ciência, Cuidado e Saúde, Maringá, v. 7, n. 
2, p. 232-240, 2008. Disponível em: < http://periodicos.uem.br/ojs/index.php/CiencCuidSaude/ article/view/5010/3246> Riscos psicossociais no Trabalho que podem levar ao estresse: uma análise da literatura>. Acesso em: 10 jan. 2014.

CARAYON, P.; SMITH, M. J.; HAIMS, M. C. Work organization, job stress, and work-related musculoskeletal disorders. Human Factors, Bethesda, v. 41, n. 4, p. 644-663, 1999. Disponível em: <http://www.ncbi.nlm.nih.gov/pubmed/10774134>. Acesso em: 25 jun. 2013.

COSTA, M. et al. Estresse: diagnóstico dos policiais militares em uma cidade brasileira. Revista Panamericana de Salud Pública, Washington v. 21, n. 4, p. 217-222, 2007. Disponível em: <http://www.scielosp.org/pdf/rpsp/v21n4/04.pdf>. Acesso em: 01 mar. 2014.

DIEHL, A. A.; TATIM, D. C. Pesquisa em Ciências Sociais Aplicadas: métodos e técnicas. São Paulo: Prentice Hall, 2004.

FARO, A.; PEREIRA, M. E. Medidas do estresse: uma revisão narrativa. Psicologia, Saúde \& Doenças, Lisboa, v. 14, n. 1, p. 101-124, 2013. Disponível em: < http://www.scielo.mec.pt/ pdf/psd/v14n1/v14n1a07.pdf> http://www.redalyc.org/pdf/362 /36226540010.pdf>. Acesso em: 22 dez. 2014.

FERRAZ, F. C.; FRANCISCO, F. R.; OLIVEIRA, C. S. Estresse no ambiente de trabalho. Archives of Health Investigation, São Paulo, v. 3, n. 5, p. 1-8, 2014. Disponível em: <http://www. archhealthinvestigation.com.br/index.php/ArcHI/article/view/797>. Acesso em: 10 jan. 2015.

FREITAS, A. K. B. Estresse, Coping e Síndrome de Burnout em Policiais Rodoviários Federais. 74 f. Dissertação (Mestrado em Engenharia da ProduçãoXXXXXX) - Universidade Federal de Santa Maria, Santa Maria, 2013. Disponível em: <http://cascavel.ufsm.br/tede//tde_busca/ arquivo.php?codArquivo=5912> Details $>$. Acesso em: 10 jan. 2015.

GARBARINO, S.; CHIORRI, C.; MAGNAVITA, N. Personality traits of the Five-Factor Model are associated with work-related stress in special force police officers. International Archives of Occupational and Environmental Health, Bethesda, v. 87, n. 3, p. 295-306, 2014. Disponível em: <http://www.ncbi.nlm.nih.gov/pubmed/23463443>. Acesso em: 12 jan. 2015.

GIL, A. C. Como elaborar projetos de pesquisa. São Paulo: Atlas, 2007.

JEX, S. M. et al. Stress e Eficácia dos Funcionários. In: ROSSI, A. M.; PERREWÉ, P. L.; SAUTER, S. L. (Org.). Stress e Qualidade de Vida no Trabalho: perspectivas atuais da saúde ocupacional. São Paulo: Atlas, 2012, p. 104-122.

KAUR, R.; CHODAGIRI, V. K.; REDDI, N. K. A Psychological Study of Stress, Personality and Coping in Police Personnel. Indian Journal of Psychological Medicine, Bethesda, v. 35, n. 2, p. 141-7, 2013. Disponível em: <http://www.ncbi.nlm.nih.gov/ pmc/articles/PMC3775045/>. Acesso em: 10 mar. 2014.

KOMPIER, M. A. J; KRISTENSEN, T. S. As intervenções em estresse organizacional: considerações teóricas, metodológicas e práticas. Cadernos de Psicologia Social do Trabalho, São Paulo, v. 6, p. 37-58, 2003. Disponível em: <http://www. gestaoebt.com.br/blog/wp-content/ files_mf/psicologia_stress_organizac_usp.pdf $>$. Acesso em: 12 maio 2013.

LAZARUS, R. S.; FOLKMAN, S. Stress. Appraisal, and coping. Nova York: Springer, 1984. 2013. 
LIMONGI-FRANÇA, A. C.; RODRIGUES, A. L. (Org.). Stress e Trabalho: uma abordagem psicossomática. São Paulo: Atlas, 2012.

LIPP, M. E. N. O Stress está dentro de você. 2. ed. São Paulo: Contexto, 2000.

LOPES, L. F. D. et al. Estatística geral. Caderno didático. 3. ed. Santa Maria: UFSM, 2008.

MA, C. C. et al. Shift Work and Occupational Stress in Police Officers. Safety and Health at Work, Bethesda, v. 6, n. 1, p. 5-29, 2015. Disponível em: <http://www.ncbi.nlm.nih.gov/pmc/ articles/PMC4372186/pdf/main.pdf >. Acesso em: 12 maio 2015.

MARRAS, J. P.; VELOSO, H. M. Estresse Ocupacional. Rio de Janeiro: Elsevier, 2012.

MARTINS, L. F. Estresse ocupacional e esgotamento profissional entre profissionais da atenção primária à saúde. $142 \mathrm{f}$. Dissertação (Mestrado em Psicologia Xxxxxx) - Universidade Federal de Juiz de Fora, Juiz de Fora, 2011. Disponível em: < http://www.ufjf.br/crepeia/ files/2009/09/estresse-ocupacional-esgotamento-profissional-atencao-primaria-saude.pdf $>$ .pdf>. Acesso em 10 out. 2013.

MENDOZA, R.; MEDEIRO, V.; COSTA, J. B. Comprometimento organizacional, fatores estressantes do trabalho e identidade social: Um estudo exploratório. Ariús - Revista de Ciências Humanas e Artes, Campina Grande, v. 13, n. 1, p. 92-100, 2007. Disponível em: <http://www. ch.ufcg.edu.br/arius/01_revistas/v13n1/09_arius_13_1_comprometimento_organizacional_fatores_estressantes_do_trabalho_e_identidade_social.pdf>. Acesso em: 10 mar. 2013.

MONTEIRO, J. K.; DALAGASPERINA, P.; QUADROS, M. O. Professores no limite: o estresse no trabalho do ensino privado no Rio Grande do Sul. Porto Alegre: Carta Editora, 2012.

OLIVEIRA, P. L. M.; BARDAGI, M. P. Estresse e comprometimento com a carreira em policiais militares. Boletim de Psicologia, São Paulo, v. 59, n. 131, p. 153-166, 2010. Disponível em: $<$ http://pepsic.bvsalud.org/pdf/bolpsi/v59n131/v59n131a03.pdf>. Acesso em: 12 mar. 2013.

PAIVA, K. C. M. et al. Estresse Ocupacional e Burnout de jovens trabalhadores. In: ENCONTRO DA ANPAD - EnANPAD, 37., Rio de Janeiro, 2013. Anais... Rio de Janeiro: ANPAD, 2013. p. 1-16, 2013. Disponível em: <http://www.anpad .org.br/admin/pdf/2013_EnANPAD_GPR63. pdf $>$. Acesso em: 22 maio 2014.

PASCHOAL, T.; TAMAYO, A. Validação da Escala de Estresse no Trabalho. Revista Estudos de Psicologia, Natal, v. 9, n. 1, p. 45-52, 2004. Disponível em: <http://www.scielo .br/pdf/ epsic/v9n1/22380.pdf>. Acesso em: 23 jan. 2013.

PEREIRA, A. M. B. Burnout: Quando o trabalho ameaça o bem-estar do trabalhador. São Paulo: Casa do Psicólogo, 2002.

SAMPAIO, J. R.; GALASSO, L. M. R. Stress no mundo do trabalho: trajetória conceitual. In: LIMONGI-FRANÇA, A. C.; RODRIGUES, A. L. (Org.). Stress e Trabalho. Uma abordagem psicossomática. 4. ed. 5. reimpr. São Paulo: Atlas, 2012, p. 65-82.

SANTOS, A. S.; CUBAS, M. R. Saúde coletiva: linhas de cuidado e consulta em enfermagem. Rio de Janeiro: Elsevier, 2012.

SELOKAR, D. et al. Occupational stress among police personnel of Wardha City India. Australasian Medical Journal, Bethesda, v. 4, n. 3, p. 114-7, 2011. Disponível em: <http://www. ncbi .nlm.nih.gov/pmc/articles/PMC3562957/>. Acesso em: 23 dez. 2014. 
TAMAYO, A. Impacto dos Valores da Organização sobre o Estresse Ocupacional. Revista de Administração Contemporânea, Rio de Janeiro, v. 1, n. 2, p. 20-33, 2007. Disponível em: $<$ http://www.anpad.org.br/periodicos/arq_pdf/a_633.pdf $>$. Acesso em: 10 fev. 2013.

WALVEKAR, S. S.; AMBEKAR, J. G.; DEVARANAVADAGI, B. B. Study on Serum Cortisol and Perceived Stress Scale in the Police Constables. Journal of Clinical and Diagnostic Research, Bethesda, v. 9, n. 2, p. 10-4, 2015. Disponível em: <http://www. ncbi.nlm.nih.gov/ pmc/articles/PMC4378726/pdf/jcdr-9-BC10.pdf>. Acesso em: 12 mar. 2015.

WELTMAN, G. et al. Police Department Personnel Stress Resilience Training: An Institutional Case Study. Global Advances in Health and Medicine, Bethesda, v. 3, n. 2, p. 72-9, 2014. Disponível em: <http://www.ncbi.nlm.nih.gov/pubmed/24808985>. Acesso em: 2 jan. 2015.

ZANELLI, J. C. (Coord.). Estresse nas organizações de trabalho. Porto Alegre: Artmed, 2010.

Recebido em: 9-1-2017

Aprovado em: 11-05-2017

Avaliado pelo sistema double blind review.

Editor: Elmo Tambosi Filho

Disponível em http://mjs.metodista.br/index.php/roc 